Article

\title{
The Moral Competence of Spanish Councilors
}

\author{
Pedro Herrero García ${ }^{1, *}$, Miguel Ángel Carbonero ${ }^{2}$ and Luis Jorge Martín Antón ${ }^{2}$ (I) \\ 1 Departamento de Psicología, Universidad de Valladolid, 47011 Valladolid, Spain \\ 2 Grupo de Investigación de Excelencia GR179 Psicología de la Educación, Departamento de Psicología, \\ Universidad de Valladolid, 47002 Valladolid, Spain; miguelangel.carbonero@uva.es (M.Á.C.); \\ luisjorge.martin@uva.es (L.J.M.A.) \\ * Correspondence: herreropedro1975@gmail.com; Tel.: +34-983-426-125
}

Received: 1 June 2020; Accepted: 29 June 2020; Published: 2 July 2020

\begin{abstract}
The citizenship's distrust of politicians clashes with the absence of research of politicians' moral competence, which is a challenge to positive psychology. The objective of this work, approved by the Spanish Federation of Municipalities and Provinces, is to measure, for the first time, the moral competence of Spanish councilors and to explore its relationship with different independent variables. A sample of 625 councilors from all the territories of the country completed a questionnaire that includes the Moral Competence Test Moral Competence Test. Estimation parameters and hypothesis contrast methods were used for the statistical analysis of the obtained data. The results indicate that most of the Spanish councilors in the sample have low moral competence, which does not depend on any of the variables contemplated in the study. Councilors with high moral competence represent only $3.7 \%$, with a profile corresponding more closely to that of people under 45 years of age, with university training, professionally linked to the private services sector, and dedicated exclusively to politics in a Town Hall.
\end{abstract}

Keywords: moral competence; corruption; policy; positive psychology; ideologization

\section{Introduction}

Throughout history, the exercise of politics has been associated with the use of lies, abuse of power, and corruption. As a result, the morality of politicians has always been questioned [1]. Spain is no exception, and the periodic barometers that have been carried out for the last 35 years by the Center for Sociological Research have been reflecting that politicians in general have usually been cited by a variable percentage of the population as one of the country's three main problems. However, this record had never reached such a high level (54\%) as it did in March 2020, placed only behind the problem of unemployment [2].

The encroachment of this bad reputation of policy-engaged people who hold posts of public responsibility [3] in the midst of the age of information is an indicator of the serious threat posed to any democratic system by the decline of the public's confidence in the proper functioning and honest administration of its institutions, especially in crisis contexts, whether economic or health crises. For this reason, the discipline of positive psychology seeks to determine the basis of this social discontent and to point out the keys to its amendment, and this should be understood as a public service, because one of its theoretical foundations is the promotion of well-being and quality of life [4]. The purpose of this work is to contribute to this through the measurement, for the first time, of the level of moral competence of a sample of local Spanish public officials who exercise their responsibilities in a way that is more closely linked to citizens' reality. 


\subsection{A Territory to Explore}

Until a decade ago, the concept of moral competence had been rarely studied from the viewpoint of psychology [5], compared to others such as emotional intelligence or leadership, and even less so concerning the exercise of politics, although this has not prevented the phenomenon of corruption, for example, from being conceptualized in terms of moral conflict or dilemma [3,6]. It is precisely in the wake of the outrage caused by major scandals of political corruption and corporate scams in a context of a global economic crisis that began in 2008 when interest arose to investigate this issue $[7,8]$, which involved the behavior of directors, managers, and people holding positions of social leadership in general, and even organizations, from large entities to small- and medium-sized businesses $[9,10]$. However, this interest has only illuminated specific studies of the public office in general, and moral competence has not yet been measured or tested in a way that allows rigorous conclusions to be reached.

The authors of [11] analyzed the contributions of social psychology to the study of the phenomenon of corruption and highlighted the paucity of research and the role of ethics through reasoning (p. 240), the key to which is in the so-called "dark triad" (narcissism, Machiavellianism and psychopathy) [12]. Likewise, the work of [13] has highlighted the influence of leaders in their promotion or eradication, which places policy makers in a determining role.

Why are these studies and assessments necessary? On the one hand, countless examples could be presented of politicians who have proven to be dishonest and to whom decision-making opportunities should never have been granted. On the other hand, there is some consensus among historians to rate Abraham Lincoln as a moral genius [14]. To reach both conclusions, it was not necessary to have the results of any moral competence tests, but it is currently unacceptable to propose the assessment of the consequences of a political leader's acts and decisions, even if it were positive. In times of Big Data and predictive analytics, laissez-faire and assessing a politician's integrity after the fact should no longer be the only option. Citizenship demands reliable evidence [1] to be able to entrust their vote and, at least, not suffer disenchantment and frustration. Now, what exactly do we mean when we refer to moral competence?

First, morality can be framed within the set of cognitive mechanisms or internal orientations that lead people to cooperate rather than to strive to achieve selfish goals [15]; that is, to try to achieve their objectives through understanding rather than through conflict, which is essential for coexistence in a diverse and pluralistic society [16]. Moral competence is, therefore, the ability to recognize that a particular problem requires a moral response and to be able to decide which, of all the possible solutions, is the most appropriate [17]. A response that, from a political point of view, can also be considered more or less intelligent [18], depending on who it benefits or harms.

Moral competence is based on universal principles, including justice [19], and it consists of the ability to solve problems and conflicts on the basis of one's moral principles through deliberation and discussion, rather than through violence and deception or submission to others [20,21]. For this reason, it can be interpreted as a democratic competence [22], which manifests itself in the ability to engage in rational and moral debate with others, especially those who have different opinions and values, through three fundamental attitudes: using and accepting arguments as a means of conflict resolution; using commonly accepted moral orientations or principles to evaluate arguments; and finally, doing so even when challenged or confronted by opponents or by those who disagree [21]. We are therefore talking about an essential competence in the exercise of politics and its processes of debate and decision-making.

People with high moral competence are those who demonstrate their ability to systematically appreciate arguments that refer to a socio-moral perspective different from their own. On the contrary, those people who only appreciate the arguments supporting their own approach and solution to the dilemma [23], that is, who only value the arguments that favor them or that go against another proposed solution, show low moral competence. The highest score is therefore attributed to people who demonstrate the ability to detect the moral quality of certain arguments versus others, regardless of 
agreeing with each of them, an aspect that represents the value of moral competence from a democratic point of view [21].

Two closely related dimensions converge in moral competence [24]. The first is the affective dimension or intuitive judgment, which is forged during the first part of life, tending to prevail when the circumstances hinder reflection, for example, due to the contextual demand for a fast response, or when the person's behavior is marked by an impulsive style that is reflected naturally in how he or she makes decisions [25]. The other dimension of moral competence is the rational one, which is slower and more explicit, and is the result of the individual cognitive processes involved in the awareness and analysis of what is right and wrong in each given situation [26]. It is also called moral reasoning and involves weighing different arguments in order to take a position and to be able to justify it under certain moral codes; a reflection and reasoning that are constructed with arguments and that, therefore, are conditioned by the use of language $[27,28]$ and the person's skill to make strategic use of it [29], which constitutes a political skill in itself.

Moral competence is therefore not an innate or immovable property that cannot evolve beyond the effects of a person's experiences and learnings during their first years of life [30] or during their education and academic training but is instead a fluid sensitivity [31] that can adapt to seek the most appropriate response to certain environmental conditions, social roles, and one's personality, provided that it is stimulated.

Conflict between the affective and rational parts of moral competence may emerge when one faces the need to express an opinion on a moral problem or dilemma. A marked tendency to take a stance impulsively to solve this dilemma without reflection reveals dogmatism, which emerges from the affective part, and which can also lead to some forms of violence [21]. If the person's only concern to deal with the debate and resolution of the dilemma is to seek argumental armor for their ideas, their explanations will be adapted to their speech, but their views will not be changed. Hence, this person will be rationalizing but not demonstrating rationality, because doing so would demonstrate their willingness to rethink their own positions and attitudes, adjusting them to shared moral principles while analyzing others' arguments and judging them according to their moral quality and not to their affinity with the person's own arguments [24].

Thus, to assess moral competence concerning a moral dilemma, it is necessary to take into account, at the same time, both the moral values and principles that sustain a person's opinion and the reasoning used to justify it, with the formation of moral judgment and moral action mediating between the two aspects [24,32]. This method is the basis for the discussion of moral dilemmas for the development of moral competence, and is the basis for the instrument that was used in this work to measure this variable in a sample of Spanish councilors.

\subsection{Where to Start}

The absence of previous studies on the moral competence of councilors justifies the performance of this research and its claim to open a line of work in this field of knowledge. Measuring the level of moral competence in a sample of Spanish councilors should help not only to clarify the reason for citizens' discontent with the supposed moral deficiencies of their representatives but also to rate some of their behaviors and decisions from a more qualified perspective.

Without similar research to replicate, similar hypotheses to refute, or equivalent published results to contrast, it is logical to think that a study like this, which can be considered preliminary, will contemplate a series of basic demographic variables that are easy to measure through a questionnaire, to explore their possible relationship with moral competence and seek some partial parallels with other studies not linked to political office or the exercise of politics [33,34]. The possible correlation between these demographic variables will allow the possibility of opening new lines of research on the factors that condition moral competence, based on the idea that moral competence can be learned $[21,35,36]$ and could therefore be included in educational or training plans for the improvement of management skills in general and political decision-making in particular. 
Therefore, in addition to the fundamental variable that is the subject of analysis of this research, moral competence, we decided to include seven other variables of a personal and professional nature. The first was age, which was taken into account as an essential demographic variable, as it may constitute a factor that, by itself, might condition the level of moral competence to the extent that direct or indirect contact with moral dilemmas throughout life may have contributed to cultivating that capacity or forbearance [7]. However, in this study, we decided to consider the hypothesis that age is not a factor influencing moral competence, even though some publications are pointing in the opposite direction [37-39], indicating age as having an inverse relationship with moral reasoning capacity.

It was also considered essential to include gender in this work when taking into account the traditional male dominance in positions of political responsibility. It is interesting to determine whether there is any significant difference between the levels of moral competence of men and women that can justify such supremacy, apart from being able to compare the results obtained with the data of an official study on the profile of Spanish councilors published in 2009 [40]. We decided to address the research considering the hypothesis of no gender differences [38], the contrast of which will allow assessing the results obtained in other studies that point to greater competence and consistency in women's moral configuration [41].

The inclusion of the variable academic training was proposed in this work to try to determine whether the level of completed studies may have a relationship with the level of moral competence, as this virtue [7] is popularly associated with a supposed preparation that is faithfully reflected in the academic record and the curriculum vitae, thus judging, a priori [1], a qualification or its lack for the performance of the office and the consequent decision-making. In this work, we considered the hypothesis that higher academic training would lead to greater moral competence, thus contrasting studies in both directions $[23,33,42]$ and comparing the data obtained with those published a decade ago by the Government of Spain, which reflected a predominant low academic level $[40,43]$.

The compatibility between the exercise of politics and employment is another variable that we decided to incorporate into this research on the premise that immersion in political life and dedication to full-time public office could have an impact on the development of moral competence, either positively, helping to face moral dilemmas with better judgment or, on the contrary, by cultivating dogmatism [24]. The study starts with the hypothesis that this academic variable is unrelated to moral competence.

We considered that the variable experience in public office should be contemplated because political experience itself may either constitute training in the field of moral competence due to the person's becoming accustomed to debating on matters with a moral charge or, on the contrary, it may be related to the consolidation of previous moral principles and dogmatism [25], preventing their contrast and evolution. We drew on the idea that neither circumstance (evolution or no evolution of the moral competence) exerts any influence and, therefore, we intended to demonstrate that moral competence does not depend on experience in public office, similar to the variable age, although one study points to a significant decrease in moral competence as of 16 years of professional experience [44].

As with the variable academic training, the variable referent professional sector was taken into consideration for this study, as it is understood that the characteristics of the employment area can have some influence on the development of moral competence and condition analysis and decision-making in issues with a moral charge linked to political activity. Similarly, the working hypothesis is that this variable plays some kind of role in the level of moral competence. Most published studies refer to students $[37,45,46]$ or specific professional profiles $[44,47]$ but not to extensive heterogeneous samples of professionals, as was intended in this study.

Finally, we also decided to include in this research the variable size of the municipality, as the selective processes for the configuration of electoral lists for local elections in Spain [48] are more competitive in cities than in small towns; hence we established the hypothesis that there is some kind of link between this variable and moral competence.

In addition to the above-mentioned seven demographic variables, another variable of a political nature was taken into account: ideologization. It is a question of whether moderation or closeness to 
the extremes [7] concerning ideological self-definition may be related to the level of moral competence, given the inconclusive studies of moral judgment and political ideology [49-51] as well as the controversy as to whether moral beliefs determine political beliefs or vice versa [52], or whether low competence in terms of moral reasoning is strongly correlated with blind obedience to authority [21]. Ideology is addressed in this study through the hypothesis that the level of ideologization contributes to explain moral competence to the extent that a greater level of moral competence is expected from those who hold temperate or moderate positions compared to those who tend to hold extreme positions on the traditional ideological game-board.

\subsection{Intention, Fingings, and Originality of this Work}

The two objectives pursued by this research are:

1. To analyze the relationship between the level of moral competence of Spanish councilors and seven variables of a personal and professional nature.

2. To analyze the relationship between the level of ideologization (extremism or moderation in ideological self-definition) and the level of moral competence.

The study finds that the majority of Spanish councilors who participated showed a low level of moral competence, while a small percentage of them have high moral competence. Likewise, the results indicate that the curriculum of the sample councilors (both their academic training and their professional experience) cannot guarantee a higher level of moral competence and, therefore, more reliability of their better capacity to make certain decisions of a moral nature in the exercise of their office. Similarly, the fact of their being young or old, women or men, having more or less political experience, representing the citizenship of a town or a city, or their professional sector of reference is no guarantee. The moral competence of the councilors of the sample is independent of all these factors. Similarly, the moral competence of the councilors who participated in this study does not depend on their ideologization.

\section{Method}

\subsection{Participants}

In this research, 625 councilors participated voluntarily; they held positions in municipalities of all sizes from each of the 50 provinces throughout the Spanish territory, of all ages, with different levels of academic training and experience in public office, belonging to various professional sectors, and with different intensity of political ideologization. Their demographic characteristics are presented in Table 1.

\subsection{Instruments}

The Spanish version of the Moral Competence Test $[32,53]$ was used (Appendix A). This instrument is composed of two moral dilemmas and evaluates the respondents' ability to apply a moral judgment structure in adverse situations, requiring them to appraise arguments with various moral orientations and collect opinions for and against the decision made by the protagonist of the dilemma. We note that the $C$ score of this test reflects the respondent's consistency of judgment of the pros and cons, such that the higher this score, the higher the moral competence attributed to the respondent (between 0 and 100 points). This competence test has a multivariate $6 \times 2 \times 2$ (six types of moral orientations, two opinions for or against, and two dilemmas in the form of stories) design. The instrument has adequate psychometric properties $[54,55]$ and construct, content, and semantic validity, and also a negative relationship with democratic attitudes and a positive one with dogmatism [56].

Participants were also requested to answer a series of questions regarding personal, professional, and political variables, grouping the response options for each one, except for gender. Specifically, 
these were: age, academic training, compatibility between public office and employment, experience in public office, the referent professional sector, and the degree of ideologization.

Table 1. Demographic characteristics of participants (valid $n=619$ ).

\begin{tabular}{|c|c|c|c|}
\hline & & $n$ & $\%$ \\
\hline \multirow[t]{3}{*}{ Age at time of survey (years) } & $<35$ & 97 & 15.7 \\
\hline & $35-54$ & 368 & 59.4 \\
\hline & $\geq 55$ & 154 & 24.9 \\
\hline \multirow[t]{2}{*}{ Gender } & Male & 396 & 64.0 \\
\hline & Female & 223 & 36.0 \\
\hline \multirow[t]{5}{*}{ Highest education Level } & $\leq$ Basic Education & 50 & 8.1 \\
\hline & High school degree & 140 & 22.6 \\
\hline & Higher formative cycle & 52 & 8.4 \\
\hline & Diploma or degree & 126 & 20.4 \\
\hline & Bachelor's degree or PhD & 251 & 40.5 \\
\hline \multirow[t]{2}{*}{ Compatibility policy-employment } & No & 308 & 49.8 \\
\hline & Yes & 311 & 50.2 \\
\hline \multirow[t]{6}{*}{ Experience in public office (years) } & $<5$ & 266 & 43.0 \\
\hline & $5-8$ & 139 & 22.5 \\
\hline & $9-12$ & 85 & 13.7 \\
\hline & $13-16$ & 56 & 9.0 \\
\hline & $17-20$ & 34 & 5.5 \\
\hline & $>20$ & 39 & 6.3 \\
\hline \multirow[t]{5}{*}{ Professional sector } & Public administration & 200 & 32.3 \\
\hline & Services & 278 & 44.9 \\
\hline & Industry or energy & 74 & 12.0 \\
\hline & Agriculture, mining, fishing & 34 & 5.5 \\
\hline & Construction & 33 & 5.3 \\
\hline \multirow[t]{5}{*}{ Municipality Size (population) } & $<1000$ & 97 & 15.7 \\
\hline & $1001-5000$ & 191 & 30.8 \\
\hline & $5001-10,000$ & 99 & 16.0 \\
\hline & $10,001-100,000$ & 189 & 30.5 \\
\hline & $>100,000$ & 43 & 7.0 \\
\hline
\end{tabular}

\subsection{Procedure}

After preparing the questionnaire, it was transcribed into digital format through a design of the Google Forms platform. Access to it was gained through the Spanish Federation of Municipalities and Provinces by an email sent to all local entities of the country encouraging participation in this research. Therefore, all the municipalities, councils, and island chapters received this email with a link to the questionnaire, although its subsequent internal distribution to the different members of the political groups of each corporation was left to each entity once the email was received, and thus the sample was obtained by a simple random method. Email delivery occurred in two waves, an initial wave on 27 April 2018 and a second wave on 21 May 2018; therefore, there was a four-week interval between them. The last questionnaire answered was registered on 16 July 2018.

As the questionnaires were answered by the councilors who voluntarily and anonymously decided to participate, the digital application of the questionnaire itself automatically recorded the answers obtained and downloaded them onto an Excel file, which stored the data for further statistical processing. From the time of the first completed questionnaire until the last one was recorded, four months elapsed, during which no electoral process took place in the country.

The entire data collection process was adapted to the provisions of the Helsinki Declaration on the protection and processing of personal data of the population under study for this type of 
research. The sampling covered more than 67,515 political representatives holding posts in the 8131 municipalities, councils, and island chapters that make up all the local entities in Spain.

Three groups of participants were formed based on their moral competence: high, medium, and low, following the instructions for the correction of the Moral Competence Test [55]. Thus, a C score between 0 and 9 points was considered low, a score between 10 and 29 points was medium, and a score higher than 30 points was considered high. The configuration of the answers concerning the personal and professional variables of the questionnaire was as follows.

The responses to the age variable were divided into three ranges. The first included people under the age of 35 , as only $5.0 \%$ of Spanish councilors were under the age of 26 a decade ago [40]. The next range covered the stage of mature workers (between 35 and 54 years), and the last range included people over 55 , considering that the average working retirement age (65 years) usually coincides with the end of most political careers and this stage represented only $4.26 \%$ [40].

Five levels were considered in academic training: the first included up to the basic level (primary studies, basic general education, or compulsory secondary education). The second referred to a high school degree or middle degree formative cycle. The third range included those councilors who had a degree equivalent to that of a higher degree formative cycle. The fourth interval corresponded to the level of diploma or degree in university studies and the fifth referred to higher studies of bachelor's degree, master's degree, or PhD. It is also of interest, in this case, to compare the sample results with those available in other studies [40].

Concerning experience in public office, six response intervals were formed, considering the unalterable duration of the four-year mandates established in the Spanish local electoral regime [57]. Regarding the variable professional sector of reference, an essential distinction was drawn between councilors with a link with the public administration and those from the private sector, specifying within the latter four options according to the economic sectors of reference: services, industry or energy sector, agriculture, mining or fishing, and, finally, the construction sector.

For the variable size of the municipality, the response distribution was divided into five categories: hamlets with a population of up to 1000 people, villages with between 1001 and 5000 inhabitants (there are 1937 villages of this size throughout the country), towns with between 5001 and 10,000 inhabitants, cities with between 10,001 and 100,000 inhabitants (there are 689 cities of these characteristics), and, finally, cities with more than 100,000 residents (there are 62 such cities in Spain).

As for the level of ideologization, the questionnaire used the 10-point Likert scale that has been used traditionally by the Sociological Research Center for the ideological self-definition of those surveyed [1], where the extremes represent the classical ideological references of left (1) and right (10) policies. Subsequently, two groups were established around the mean obtained by the sample (3.71 points): one of marked or strong ideologization (self-description at levels 1, 7, 8, 9, and 10 of the scale) and moderate or weak (corresponding to the remaining levels 2, 3, 4, 5, and 6).

\subsection{Data Analysis}

After verifying the parametric assumptions, one-way analysis of variance (ANOVA) and $t$-tests were used for independent samples to determine possible significant differences in the moral competence score between the different groups in the target variables. The chi-square statistic $\left(\chi^{2}\right)$ was also calculated to determine possible differences in the frequency of cases in each of the target variables as a function of the levels of moral competence (low, medium, and high). Moreover, the Standardized residuals (SR) were calculated, taking as a criterion of significant differences in frequency a value exceeding the range $[-1.96,1.96]$. For this purpose, we used the statistical package IBM SPSS Statistics, version 26 (2019). All statistical analyses used had a 95\% confidence level. 


\section{Results}

According to the above-mentioned standardization established by the Moral Competence Test [54], most participating councilors $(52.3 \%)$ presented a low level of moral competence [C $<10]$, and the mean C score [C 10-30] of the sample, albeit at a medium level, was close to the low range limit $(M=11.0)$. Similarly, $47.2 \%$ of the sample councilors were at a medium or high level, although a minority $(n=23)$ of them presented a high level [C > 30] of moral competence (Table 2).

Table 2. Sample distribution, mean, and standard deviation as a function of the degree of moral competence.

\begin{tabular}{ccccc}
\hline Moral Competence $^{\mathbf{1}}$ & $\boldsymbol{n}$ & $\mathbf{\%}$ & $\boldsymbol{M}$ & $\boldsymbol{S D}$ \\
\hline Low [C < 10] & 327 & 52.8 & 5.17 & 2.71 \\
Medium [C 10-30] & 269 & 43.5 & 16.17 & 4.78 \\
High [C > 30] & 23 & 3.7 & 34.34 & 3.89 \\
\hline
\end{tabular}

${ }^{1}$ The maximum $\mathrm{C}$ score is 100

As for the ratio of the first demographic variable taken into account in this study, age, as related to the level of moral competence ( $\mathrm{C}$ score), Table 3 shows that the average scores in moral competence of the three age groups were similar, with no significant differences $\left(\chi^{2}=4.17 ; p=0.38\right)$. On the other hand, Table 4 shows that the percentage weight of individuals under the age of 35 increases with the level of moral competence. Similarly, the representation of councilors aged 55 years or older decreased in the group with high moral competence $(8.7 \%$ versus $24.5 \%$ and $26.8 \%$, respectively, for those who obtained a low or medium C score). However, these group differences (Table 4 ) were nonsignificant. The analysis of variance (Table 5) indicates that moral competence does not depend on age $(p=0.75)$.

Table 3. Means and standard deviations on measure of age-moral competence.

\begin{tabular}{cccc}
\hline & \multicolumn{3}{c}{ C Score $^{\mathbf{1}}$} \\
\hline Age Group & $\boldsymbol{n}$ & $\boldsymbol{M}$ & $\boldsymbol{S D}$ \\
\hline$<35$ & 97 & 11.21 & 8.20 \\
$35-54$ & 368 & 11.16 & 8.33 \\
$\geq 55$ & 154 & 10.60 & 7.07 \\
\hline
\end{tabular}

${ }^{1}$ The maximum score is 100 .

Table 4. Crosstab of age-moral competence level.

\begin{tabular}{|c|c|c|c|c|c|}
\hline \multirow{2}{*}{ Age Group } & & \multicolumn{4}{|c|}{ C Score } \\
\hline & & Low & Medium & High & Total \\
\hline \multirow[t]{3}{*}{$<35$} & $f$ & 49 & 43 & 5 & 97 \\
\hline & $\%$ & $15.0 \%$ & $16.0 \%$ & $21.7 \%$ & $15.7 \%$ \\
\hline & $S R$ & -0.3 & 0.1 & 0.7 & \\
\hline \multirow[t]{3}{*}{$35-54$} & $f$ & 198 & 154 & 16 & 368 \\
\hline & $\%$ & $60.5 \%$ & $57.2 \%$ & $69.6 \%$ & $59.4 \%$ \\
\hline & $S R$ & 0.3 & -0.5 & 0.6 & \\
\hline \multirow[t]{3}{*}{$\geq 55$} & $f$ & 80 & 72 & 2 & 154 \\
\hline & $\%$ & $24.5 \%$ & $26.8 \%$ & $8.7 \%$ & $24.9 \%$ \\
\hline & $S R$ & -0.2 & 0.6 & -1.6 & \\
\hline
\end{tabular}


Table 5. Analysis of variance (ANOVA) of age-moral competence.

\begin{tabular}{cccccc}
\hline & $d f$ & $S S$ & $M S$ & $\boldsymbol{F}$ & $p$ \\
\hline Between groups & 2 & 37.77 & 18.88 & 0.29 & 0.75 \\
Within groups & 616 & $39,624.48$ & 64.32 & & \\
Total & 618 & $39,662.25$ & & & \\
\hline
\end{tabular}

Regarding the second target variable, gender, the comparison of the $C$ scores of men $(M=11.08$, $S D=8.14)$ and women $(M=10.95, S D=7.78)$ was nonsignificant $(t=0.99)$. Concerning the level of moral competence, $63.9 \%$ of the councilors in the sample who had a low or medium $C$ score were men, whereas $65.2 \%$ of the men presented high moral competence (Table 6). Similarly, the analysis of variance showed that gender does not condition moral competence because $p=0.85$ (Table 7).

Table 6. Crosstab of gender-level of moral competence.

\begin{tabular}{cccccc}
\hline \multirow{2}{*}{ Gender } & \multicolumn{5}{c}{ C Score } \\
\cline { 2 - 6 } & & Low & Medium & High & Total \\
\hline \multirow{2}{*}{ Male } & $f$ & 209 & 172 & 15 & 396 \\
& $\%$ & $63.9 \%$ & $63.9 \%$ & $65.2 \%$ & $64.0 \%$ \\
& $S R$ & 0.0 & 0.0 & 0.1 & \\
\hline \multirow{2}{*}{ Female } & $f$ & 118 & 97 & 8 & 223 \\
& $\%$ & $36.1 \%$ & $36.1 \%$ & $34.8 \%$ & $36.0 \%$ \\
& $S R$ & 0.0 & 0.0 & 0.0 & \\
\hline
\end{tabular}

Table 7. ANOVA of gender-moral competence.

\begin{tabular}{cccccc}
\hline & $d f$ & $S S$ & $M S$ & $\boldsymbol{F}$ & $p$ \\
\hline Between groups & 1 & 2.23 & 2.23 & 0.35 & 0.85 \\
Within groups & 617 & $39,660.02$ & 64.28 & & \\
Total & 618 & $39,662.25$ & & & \\
\hline
\end{tabular}

With regards to the variable of academic training, Table 8 presents the differences between the data reflected in the 2009 [40] Spanish governmental study of Spanish councilors and those obtained with the councilors who participated in this research: $60.9 \%$ of our sample had university studies, which is almost double (32.8\%) that of the national study in 2009. In Spain, 37.3\% of the population currently has higher education (almost 15 points more than 20 years ago and eight points more than in 2008) [43]. At the same time, $37.2 \%$ of the councilors had basic or lower studies, according to the ministerial study, versus $8.1 \%$ of the data in this sample, with significant differences $\left(\chi^{2}=88.85 ; p<0.001\right)$.

Table 8. Comparison of academic training data ${ }^{1}$ with data obtained in this work.

\begin{tabular}{ccc}
\hline Highest Education Level & $\mathbf{\%}$ & $\mathbf{\%}$ \\
\hline SBasic education & 37.2 & 8.1 \\
High school degree & 22.4 & 22.6 \\
Higher formative cycle & 7.6 & 8.4 \\
Diploma or degree & 15.6 & 20.4 \\
Bachelor's degree or PhD & 17.2 & 40.5 \\
\hline
\end{tabular}

$\%$ corrected by removing the distorting effect of the No Response / Do not Know option.

The average $C$ scores for each interval of academic level (Table 9) were nonsignificant because $\chi^{2}=4.51$ and $p=0.81$. Among the participants in this study who showed high moral competence, $74 \%$ had a university academic level (Table 10). The level of moral competence as a whole did not depend 
on the academic training of the participant councilors according to the analyses of variance (Table 11), as $p=0.97$.

Table 9. Means and standard deviations on measure of highest education level-moral competence.

\begin{tabular}{cccc}
\hline & \multicolumn{2}{c}{ C Score $^{\mathbf{1}}$} \\
\hline Highest Education Level & $\boldsymbol{n}$ & $\boldsymbol{M}$ & $\boldsymbol{S D}$ \\
\hline sBasic education & 50 & 10.58 & 6.96 \\
High school degree & 140 & 10.74 & 7.72 \\
Higher formative cycle & 52 & 11.00 & 7.39 \\
Diploma or degree & 126 & 11.22 & 8.95 \\
Bachelor's degree or PhD & 251 & 11.19 & 8.01 \\
\hline
\end{tabular}

${ }^{1}$ The maximum $\mathrm{C}$ score is 100 .

Table 10. Crosstab of highest education level-moral competence level.

\begin{tabular}{cccccc}
\hline & \multicolumn{5}{c}{ C Score } \\
\hline Highest Education Level & & Low & Medium & High & Total \\
\hline B Basic Education & $f$ & 27 & 22 & 1 & 50 \\
& $\%$ & $8.2 \%$ & $8.1 \%$ & $4.3 \%$ & $8.1 \%$ \\
& $S R$ & 0.1 & 0.1 & -0.6 & \\
\hline High school degree & $f$ & 76 & 61 & 3 & 140 \\
& $\%$ & $23.2 \%$ & $22.7 \%$ & $13.0 \%$ & $22.6 \%$ \\
& $S R$ & 0.2 & 0.0 & -1.0 & \\
\hline Higher formative cycle & $f$ & 26 & 24 & 2 & 52 \\
& $\%$ & $8.0 \%$ & $8.9 \%$ & $8.7 \%$ & $8.4 \%$ \\
& $S R$ & -0.3 & 0.3 & 0.0 & \\
\hline Diploma or degree & $f$ & 68 & 50 & 8 & 126 \\
& $\%$ & $20.8 \%$ & $18.6 \%$ & $34.8 \%$ & $20.4 \%$ \\
& $S R$ & -0.2 & -0.6 & 1.5 & \\
\hline Bachelor's degree or PhD & $f$ & 130 & 112 & 9 & 251 \\
& $\%$ & $39.8 \%$ & $41.7 \%$ & $39.2 \%$ & $40.5 \%$ \\
& $S R$ & -0.2 & 0.3 & -0.1 & \\
\hline
\end{tabular}

Table 11. ANOVA of highest education level-moral competence.

\begin{tabular}{cccccc}
\hline & $d f$ & $S S$ & MS & $\boldsymbol{F}$ & $p$ \\
\hline Between groups & 4 & 33.24 & 8.31 & 0.13 & 0.97 \\
Within groups & 614 & $39,629.00$ & 64.54 & & \\
Total & 618 & $39,662.25$ & & & \\
\hline
\end{tabular}

Concerning the variable of compatibility between politics and employment, on the one hand, participants who were exclusively engaged in politics had a higher mean $(M=11.39, S D=8.61)$ than those who combined both activities, either permanently $(M=10.84, S D=7.48)$, or occasionally $(M=9.61, S D=6.46)$, although this difference was nonsignificant $(t=0.32)$.

Regarding the relationship of this variable with the level of moral competence, the analysis indicates that, among those with low moral competence, $49.2 \%$ were dedicated exclusively to politics, and $43.7 \%$ permanently balanced politics with their employment, and the remaining $7.0 \%$ did so occasionally. Among those with average moral competence, these figures were $49.1 \%, 43.9 \%$, and $7.1 \%$, respectively. Among those who presented high moral competence, $65.2 \%$ were dedicated exclusively to politics and the rest permanently combined politics and employment. The analysis of variance of the two variables is presented in Table 12 and shows that they have no relationship with each other, 
confirming the initial hypothesis, as there were no statistically significant differences between those who combine politics and employment and those who do not $(p=0.35)$.

Table 12. ANOVA of compatibility-moral competence.

\begin{tabular}{cccccc}
\hline & $d f$ & $S S$ & $M S$ & $F$ & $p$ \\
\hline Between groups & 2 & 134.00 & 67.00 & 1.04 & 0.35 \\
Within groups & 616 & $39,528.25$ & 64.16 & & \\
Total & 618 & $39,662.25$ & & & \\
\hline
\end{tabular}

With regards to the variable of experience in public office, the highest mean C Score $(M=13.18)$ was observed in the group of councilors with between 17 and 20 years' experience in public office, and the lowest score was obtained precisely in the previous section of 9 to 12 years $(M=9.19)$, and thus no differences were found in this regard (Table 13) as $\chi^{2}=14.03$ and $p=0.17$.

Table 13. Means and standard deviations on measure of experience in public office-moral competence.

\begin{tabular}{cccc}
\hline & \multicolumn{2}{c}{ C Score $^{\mathbf{1}}$} \\
\hline Experience in Public Office (Years) & $\boldsymbol{n}$ & $\boldsymbol{M}$ & $\boldsymbol{S D}$ \\
\hline$<5$ & 266 & 10.99 & 8.03 \\
$5-8$ & 139 & 10.91 & 8.38 \\
$9-12$ & 85 & 11.27 & 7.29 \\
$13-16$ & 56 & 9.19 & 6.83 \\
$17-20$ & 34 & 13.18 & 8.99 \\
$>20$ & 39 & 11.97 & 7.16 \\
\hline
\end{tabular}

${ }^{1}$ The maximum C score is 100 .

Table 13 depicts the analysis of the relationship between the variables experience in public office and the level of moral competence. A total of $91.3 \%$ of the posts that had high moral competence had less than 12 years' experience in public office, whereas $80.4 \%$ and $76.5 \%$ showed low and medium moral competence, respectively. In Table 14, we can see the analysis of variance between the two variables, with no statistically significant differences between the groups of experience in public office $p=0.30$ (Table 15); hence experience in public office was not related to moral competence, confirming the hypothesis.

With regards to the variable professional sector, Table 16 shows that the highest mean score of moral competence ( $C$ score) of the sample occurred in the private services sector $(M=11.45)$, whereas the lowest was in the agriculture, mining, or fishing sectors $(M=9.84)$, although this difference was nonsignificant $\left(\chi^{2}=6.94\right.$ and $\left.p=0.54\right)$.

Similarly, Table 17 presents the analysis of the relationship between professional sector variables and the level of moral competence. Of those who showed low and medium moral competence, 33.3\% and $32.3 \%$, respectively, were linked to the public sector, whereas this percentage decreased to $17.4 \%$ among those with high moral competence. By contrast, there was a higher percentage $(69.6 \%)$ of people in the private services sector with a high C score than of those who had a low $(43.5 \%)$ or medium $(44.7 \%)$ C score.

Table 18 presents the analysis of variance between the two variables, indicating that the referent professional sector did not determine the level of moral competence, as there were no statistically significant variations between the different professional sectors $(p=0.69)$. 
Table 14. Crosstab of experience in public office-moral competence level.

\begin{tabular}{cccccc}
\hline & \multicolumn{5}{c}{ C Score } \\
\hline Experience in Public Office (Years) & & Low & Medium & High & Total \\
\hline$<$ & $f$ & 141 & 115 & 10 & 266 \\
& $\%$ & $43.0 \%$ & $42.7 \%$ & $43.5 \%$ & $43.0 \%$ \\
& $S R$ & 0.0 & 0.0 & 0.0 & \\
\hline $5-8$ & $f$ & 78 & 54 & 7 & 139 \\
& $\%$ & $23.9 \%$ & $20.0 \%$ & $30.4 \%$ & $22.5 \%$ \\
& $S R$ & 0.5 & -0.8 & 0.8 & \\
\hline $9-12$ & $f$ & 44 & 37 & 4 & 85 \\
& $\%$ & $13.5 \%$ & $13.8 \%$ & $17.4 \%$ & $13.7 \%$ \\
& $S R$ & 0.5 & -0.8 & 0.8 & \\
\hline $13-16$ & $f$ & 34 & 22 & 0 & 56 \\
& $\%$ & $10.4 \%$ & $8.2 \%$ & $0 \%$ & $9.0 \%$ \\
& $S R$ & 0.8 & -0.5 & -1.4 & \\
\hline $17-20$ & $f$ & 10 & 22 & 2 & 34 \\
& $\%$ & $3.1 \%$ & $8.2 \%$ & $8.7 \%$ & $5.5 \%$ \\
& $S R$ & -1.9 & 1.9 & 0.7 & \\
\hline$>20$ & $f$ & 20 & 19 & 0 & 39 \\
& $\%$ & $6.1 \%$ & $7.1 \%$ & $0 \%$ & $6.3 \%$ \\
& $S R$ & -0.1 & 0.5 & -1.2 & \\
\hline
\end{tabular}

Table 15. ANOVA of experience in public office-moral competence.

\begin{tabular}{cccccc}
\hline & $d f$ & $S S$ & $M S$ & $\boldsymbol{F}$ & $p$ \\
\hline Between groups & 5 & 388.87 & 77.77 & 1.21 & 0.30 \\
Within groups & 613 & $39,273.38$ & 64.06 & & \\
Total & 618 & $39,662.25$ & & & \\
\hline
\end{tabular}

Table 16. Means and standard deviations on measure sector professional-moral competence.

\begin{tabular}{cccc}
\hline & \multicolumn{2}{c}{ C Score $^{\mathbf{1}}$} \\
\hline Professional Sector & $\boldsymbol{n}$ & $\boldsymbol{M}$ & $\boldsymbol{S D}$ \\
\hline Public administration & 200 & 10.68 & 7.21 \\
Services & 278 & 11.45 & 8.80 \\
Industry or energy & 74 & 11.30 & 7.79 \\
Agriculture, mining, fishing & 34 & 9.84 & 6.72 \\
Construction & 33 & 10.29 & 739 \\
\hline
\end{tabular}

${ }^{1}$ The maximum C score is 100 .

With regards to the variable size of the municipality, Table 19 reflects the $\mathrm{C}$ score means for the sample councilors for each of the municipal categories, ranging from [1001-5000] $(M=10.62)$ to $[>100,000](M=12.87)$ with no significant differences $\left(\chi^{2}=5.83\right.$ and $\left.p=0.67\right)$.

Also regarding municipality size, and specifically municipalities of more than 10,000 inhabitants, it can be observed that the percentage of councilors with a low and medium $C$ score was similar $(37.0 \%$ and $36.8 \%$, respectively), whereas it increased to $52.2 \%$ for councilors with a high score, as shown in Table 20. Similarly, regarding populations exceeding 100,000 inhabitants, $5.5 \%$ of those who obtained a low moral competence score were in this range, whereas $8.2 \%$ obtained a medium score, and $13.0 \%$ had a high C score in the Moral Competence Test. Nonetheless, the size of the municipality did not determine the moral competence of the councilors according to the variance analysis (Table 21), so the initial hypothesis was not confirmed, as no statistically significant variations were found between the different population size categories $(p=0.51)$. 
Table 17. Crosstab of professional sector-level of moral competence.

\begin{tabular}{cccccc}
\hline & \multicolumn{5}{c}{ C Score } \\
\hline Professional Sector & & Low & Medium & High & Total \\
\hline Agriculture, mining, fishing & $f$ & 19 & 15 & 0 & 34 \\
& $\%$ & $5.8 \%$ & $5.6 \%$ & $0 \%$ & $5.5 \%$ \\
& $S R$ & 0.2 & 0.1 & -1.1 & \\
\hline Industry or energy & $f$ & 38 & 34 & 2 & 74 \\
& $\%$ & $11.6 \%$ & $12.6 \%$ & $8.7 \%$ & $12.0 \%$ \\
& $S R$ & -0.2 & 0.3 & -0.5 & \\
\hline Construction & $f$ & 19 & 13 & 1 & 33 \\
& $\%$ & $5.8 \%$ & $4.8 \%$ & $4.3 \%$ & $5.3 \%$ \\
& $S R$ & 0.4 & -0.4 & -0.2 & \\
\hline Services & $f$ & 142 & 120 & 16 & 278 \\
& $\%$ & $43.5 \%$ & $44.7 \%$ & $69.6 \%$ & $44.9 \%$ \\
& $S R$ & -0.4 & 0.0 & 1.8 & \\
\hline Public administration & $f$ & 109 & 87 & 4 & 200 \\
& $\%$ & $33.3 \%$ & $32.3 \%$ & $17.4 \%$ & $32.3 \%$ \\
& $S R$ & -0.4 & 0.0 & 1.8 & \\
\hline
\end{tabular}

Table 18. ANOVA of professional sector-moral competence.

\begin{tabular}{cccccc}
\hline & $d f$ & SS & MS & $\boldsymbol{F}$ & $p$ \\
\hline Between groups & 4 & 144.31 & 36.07 & 0.56 & 0.69 \\
Within groups & 614 & $39,517.93$ & 64.36 & & \\
Total & 618 & $39,662.25$ & & & \\
\hline
\end{tabular}

Table 19. Means and standard deviations on measure size of the municipality-moral competence.

\begin{tabular}{cccc}
\hline & \multicolumn{3}{c}{ C Score $^{\mathbf{1}}$} \\
\hline Municipality Size (Population) & $\boldsymbol{n}$ & $\boldsymbol{M}$ & SD \\
\hline$<1000$ & 97 & 11.51 & 7.86 \\
$1001-5000$ & 191 & 10.62 & 7.93 \\
$5001-10,000$ & 99 & 11.01 & 8.17 \\
$10,001-100,000$ & 189 & 10.79 & 8.05 \\
$>100,000$ & 43 & 12.87 & 8.17 \\
\hline
\end{tabular}

${ }^{1}$ The maximum $\mathrm{C}$ score is 100

Finally, as regards the relationship between the variable ideologization and the level of moral competence, we note that the councilors of the sample with a strong ideologization $(n=194 ; 31.3 \%)$ obtained a lower mean $(M=10.61, S D=7.97)$ than those with a weak ideologization $(n=425, M=11.22$; $S D=8.03$ ), but without reaching statistical significance $t(2)=0.25, p=0.88$. Among those presenting low moral competence, $31.8 \%$ (Table 22) were highly ideologized (regardless of the political tendency in the classic distinction between the left-right poles). A total of $30.5 \%$ of the highly ideologized people presented medium moral competence, and $34.8 \%$ had high moral competence. The analysis of variance (Table 23) revealed that the two variables are unrelated, as $p=0.38$. 
Table 20. Crosstab of municipality size-level of moral competence.

\begin{tabular}{cccccc}
\hline & \multicolumn{5}{c}{ C Score } \\
\hline Municipality Size (Population) & & Low & Medium & High & Total \\
\hline$<1000$ & $f$ & 48 & 47 & 2 & 97 \\
& $\%$ & $14.7 \%$ & $17.5 \%$ & $8.7 \%$ & $15.7 \%$ \\
& $S R$ & -0.5 & 0.7 & -0.8 & \\
\hline $1001-5000$ & $f$ & 105 & 80 & 6 & 191 \\
& $\%$ & $32.1 \%$ & $29.7 \%$ & $26.1 \%$ & $30.9 \%$ \\
& $S R$ & 0.4 & -0.3 & -0.4 & \\
\hline $5001-10,000$ & $f$ & 53 & 43 & 3 & 99 \\
& $\%$ & $16.2 \%$ & $16.0 \%$ & $13.0 \%$ & $16.0 \%$ \\
& $S R$ & 0.1 & 0.0 & -0.4 & \\
\hline $10,001-100,000$ & $f$ & 103 & 77 & 9 & 189 \\
& $\%$ & $31.5 \%$ & $28.6 \%$ & $39.2 \%$ & $30.5 \%$ \\
& $S R$ & 0.3 & -0.6 & 0.7 & \\
\hline 100,000 & $f$ & 18 & 22 & 3 & 43 \\
& $\%$ & $5.5 \%$ & $8.2 \%$ & $13.0 \%$ & $6.9 \%$ \\
& $S R$ & -1.0 & 0.8 & 1.1 & \\
\hline
\end{tabular}

Table 21. ANOVA of municipality size-moral competence.

\begin{tabular}{cccccc}
\hline & $d f$ & $S S$ & MS & $\boldsymbol{F}$ & $\boldsymbol{p}$ \\
\hline Between groups & 4 & 210.64 & 52.66 & 0.82 & 0.51 \\
Within groups & 614 & $39,451.61$ & 64.25 & & \\
Total & 618 & $39,662.25$ & & & \\
\hline
\end{tabular}

Table 22. Crosstab of ideologization-level of moral competence.

\begin{tabular}{cccccc}
\hline & \multicolumn{5}{c}{ C Score } \\
\hline Ideologization & & Low & Medium & High & Total \\
\hline Strong & $f$ & 104 & 82 & 8 & 194 \\
& $\%$ & $31.8 \%$ & $30.5 \%$ & $34.8 \%$ & $31.3 \%$ \\
& $S R$ & 0.1 & -0.3 & 0.3 & \\
\hline Weak & $f$ & 223 & 187 & 15 & 425 \\
& $\%$ & $68.2 \%$ & $69.5 \%$ & $65.2 \%$ & $68.7 \%$ \\
& $S R$ & -0.1 & 0.2 & -0.2 & \\
\hline
\end{tabular}

Table 23. ANOVA of ideologization-moral competence.

\begin{tabular}{cccccc}
\hline & $d f$ & $S S$ & $M S$ & $\boldsymbol{F}$ & $p$ \\
\hline Between groups & 1 & 50.01 & 50.01 & 0.78 & 0.38 \\
Within groups & 617 & $39,612.24$ & 64.20 & & \\
Total & 618 & $39,662.25$ & & & \\
\hline
\end{tabular}

\section{Discussion and Conclusions}

The obtained results confirm some of the hypotheses contemplated. As expected, the moral competence of the Spanish councilors who participated in the study did not depend on their age, gender, on how they combine their post with a job, or their years of experience in the exercise of public office. Contrary to our expectations, the data obtained about the other variables cannot explain this variable either-the academic level, the professional sector, the size of the municipality, or the ideologization.

The average level of moral competence of the whole sample $(M=11.0)$ can be considered low taking into account the range of the medium level [C 10-30], which reveals a possible dogmatism 
factor of the councilors who participated in the research; that is, a remarkable rigidity in dealing with moral tasks with a marked tendency to follow the pattern of moral reasoning preferred by their ideological tendency. However, the $\mathrm{C}$ scores obtained by the councilors of the sample correspond to those obtained in most research carried out with the Moral Competence Test [23]; thus, to determine whether the level of moral competence of the Spanish councilors faithfully reflects the level of moral competence of society or any particular sector of it, it would be necessary to replicate the study with another representative sample of the Spanish population that does not hold any public office. Similarly, to expand the study population to all politicians, it would be necessary to extend the research to other levels of the state administration, as well as to other countries.

The fact that $36.0 \%$ of the sample was composed of female councilors, when that percentage accounted for $30.5 \%$ in the study conducted a decade ago [40], allows us to consider it representative if we take into account the legal framework that narrows the presence on the electoral lists of either sex to $60 \%$, thus limiting the traditional male predominance on those lists $[55,57]$. However, men still continue to occupy the top positions in each 5-member tranche of the lists, taking into account the number of representatives per entity [57], and thus men are still more likely to be elected, which explains the percentage distribution obtained in the sample, although some progress could be observed [40]. The equal moral competence of men and women in this study refutes the contradiction between the results of the studies taken into account $[38,41]$.

The councilors of the sample had a higher academic background than the current average of the Spanish population [43], a difference that was not as marked a decade ago [40]. On the one hand, the councilors who decided to answer the questionnaire may have been precisely those who were most trained. On the other hand, it is not possible to know whether this alleged improvement in the academic level in a decade has also led to an improvement in the level of moral competence, as we lack antecedents. The results indicate that the compatibility of holding a post in public office and a job does not imply either an advantage or a disadvantage in moral competence, and the same was observed with the variable experience in public office.

The fact that a significantly larger number of councilors with high moral competence was more closely linked to the private sector than the sample as a whole (especially in the services sector) highlights the need to explore the scope of certain functional and formative transfers between the public and private spheres in order to improve the management of the institutions. As far as the sample is concerned, the lack of a relationship between ideologization and moral competence is of interest for new research [7], as theoretical foundation supports the argument that dogmatism is related to strong ideology.

Although none of the target variables of the study correlated with moral competence, the profile of the councilors of the sample with high C scores corresponded more, albeit not significantly enough, with people under the age of 55 , with university studies, linked to the service sector, and who carry out their public role in large cities. The impossibility of generalizing the differential characteristics of the profile of these councilors with high moral competence to the entire study population is due to the poor representativeness of this group within the sample.

In light of the results obtained, it is recommended to focus research towards seeking a correlation of moral competence with emotional intelligence [5]. The same can be said of verbal skills, whose development could condition the quality of moral reasoning [27,29], as well as with religiosity $[58,59]$ or the incidence of corruption [11]. Given the implementation of this variable in educational and training programs [35], the integration of the moral component in its design, with a view to the selection processes to access positions of responsibility, whether in the field of political management or in general, can lead to a qualitative improvement and the achievement of greater guarantees for those who depend on their decisions.

Finally, these results constitute a reference that until now did not exist and that can serve to inspire new research along the lines of this work, since investigating the keys to the moral competence of our public officials is a democratic necessity to which psychology in general and positive psychology 
in particular can give an answer. If, as it seems, the key is not in the academic qualification, political experience, or the rest of the variables considered in this study, an experimental design around training in moral competence should be considered.

Author Contributions: Theoretical framework, design, data collection or interpretation, P.H.G., L.J.M.A. and M.Á.C. All authors have read and agreed to the published version of the manuscript.

Funding: This research received no external funding.

Acknowledgments: Administrative and technical support was provided by Federación Española de Municipios y Provincias (FEMP) through the use of its database and the distribution of the questionnaire to all local entities in the country.

Conflicts of Interest: The authors declare no conflict of interest.

\section{Appendix A}

For the choice of the instrument for measuring moral competence, different options were considered. First, the Moral Competence Test [32] inspired by Kohlberg's theory of moral development was used. Second, the Moral Judgment Test [60] was chosen for responding to a dual theoretical framework of moral competence and for the simplicity of its administration, with the permission of its author. This questionnaire covers the need to assess the capacity of moral judgment of the study participants in adverse situations, registering their arguments with different moral orientations and collecting opinions in favor and against the decision of the character that takes sides in the dilemma. Consequently, the use of the moral judgment interview was ruled out [61] because, although it is a semi-structured interview on three moral dilemmas that urges an approximate position regarding conflicting values, it follows an individualized method and is therefore enormously costly in terms of correction time: it must be administered orally and, if possible, recorded in order to be later transcribed. In the same way, the use of the Defining Issues Test [62] was also ruled out for responding to a theoretical model very similar to the previous one, which is very much attached to the reference of the Kohlberg stages [19]. This is a self-administered test with multiple choice answer on moral dilemmas. The person must choose the answer among twelve options with a scale of five degrees of importance for their resolution, a format similar to the Moral Competence Test. However, the person must order the four alternatives that he considers most important for solving the dilemma, adding more difficulty and time.

\section{References}

1. Proverbia.net. Available online: https://proverbia.net/frases-de-politica (accessed on 7 April 2020).

2. Centro de Investigaciones Sociológicas. Barómetro de enero de 2020. Available online: http://datos.cis.es/ pdf/Es3271rei_A.pdf (accessed on 8 April 2020).

3. Nick, C. The Problem of Dirty Hands in Democracies. Ph.D. Thesis, University of Leeds, Leeds, UK, 2019.

4. Poseck, B.V. Psicología positiva: Una nueva forma de entender la psicología. Papeles del Psicólogo 2006, 27, 3-8.

5. Kiel, F.; Lennick, D. Moral Intelligence: Enhancing Business Performance and Leadership Success; Pearson Education: London, UK, 2005.

6. Martelo, M.F.G. Un estudio psicológico de actitudes corruptas desde la perspectiva de la acción moral. Boletín de Psicología 2004, 80, 7-36.

7. Fontrodona, J.; Sanz, P. La moderación como competencia moral: Integrando perspectivas para una mejor comprensión de la templanza en el lugar de trabajo. J. Bus. Ethics 2019, 155, 981-994.

8. Kim, T.Y.; Kim, M. Leaders' moral competence and employee outcomes: The effects of psychological empowerment and person-supervisor fit. J. Bus. Ethics 2013, 112, 155-166. [CrossRef]

9. Adla, L.; Eyquem-Renault, M.; Gallego-Roquelaure, V. De los valores del líder a los valores organizacionales: Hacia una visión dinámica y experimental sobre el trabajo de valor en las PYME. M@n@gement 2020, 81-101. [CrossRef] 
10. Morales-Sánchez, R.; Cabello-Medina, C. The role of four universal moral competencies in ethical decision-making. J. Bus. Ethics 2013, 116, 717-734. [CrossRef]

11. Julián, M.; Bonavia, T. Psychological variables related to corruption: A systematic review. Ann. Psychol. 2020, 36, 330-339. [CrossRef]

12. Zhao, H.; Zhang, H.; Xu, Y. Does the dark triad of personality predict corrupt intention? The mediating role of belief in good luck. Front. Psychol. 2016, 7, 1-16. [CrossRef]

13. Hechanova, M.R.M.; Melgar, I.; Falguera, P.Z.; Villaverde, M. Organisational culture and workplace corruption in government hospitals. J. Pac. Rim Psychol. 2014, 8, 62-70. [CrossRef]

14. McIver, S.B.; Ridings, W.J. Rating the Presidents: A Ranking of US Leaders, from the Great and Honorable to the Dishonest and Incompetent; Citadel Press: New York, NY, USA, 2000.

15. Decety, J.; Wheatley, T. (Eds.) The Moral Brain: A Multidisciplinary Perspective; MIT Press: Cambridge, MA, USA, 2015.

16. Chisholm, L.; Ostendorf, A.; Thoma, M.; Weber, W. Democratic Competences and Social Practices in Organizations; Springer Science and Business Media: Wiesbaden, Germany, 2012; pp. 62-85.

17. Dwyer, S. Moral competence. In Philosophy and Linguistics; Routledge: Abingdon, UK, 2019; pp. $169-190$.

18. Cipolla, C.M. Las leyes fundamentales de la estupidez humana. Cuadernos de Economía 1996, 15, $200-216$.

19. Kohlberg, L. Psicología del Desarrollo Moral; Desdée de Broower: Bilbao, España, 1992.

20. Lind, G. Moral ist Lehrbar. Wie Man Moralisch-Demokratische Fähigkeiten Fördern und Damit Gewalt, Betrug und Macht Mindern kann. 3. Erweitere, Überarbeitete Auflage; Logos: Berlin, Germany, 2015; Available online: http://www.uni-konstanz.de/ag-moral/mut/mjt-intro.htm\#mut_sample (accessed on 30 April 2020).

21. Lind, G. Promoviendo las competencias morales y democráticas: Expresarse y escuchar a otros. Postconvencionales 2011, 3, 26-41.

22. Messina, G.; Pizarro, C.; Palma, E.; Messina, G. Socialización política de los niños en América Latina: Un ensayo de articulación desde la teoría. In Niñez y Democracia; Pizarro, C., Palma, E., Eds.; Ariel. Santafé de Bogotá: Bogotá, DC, USA, 1997; pp. 161-195.

23. Lind, G. Scoring and Interpreting MCT. 2015. Available online: https://www.uni-konstanz.de/ag-moral/mut/ mjt-intro.htm (accessed on 10 May 2020).

24. Lind, G. How to Teach Morality: Promoting Deliberations, Discussion, Reducing Violence and Deceit; The Log Berlin: Berlin, Germany, 2016.

25. Haidt, J.; Joseph, C. The moral mind: How five sets of innate intuitions guide the development of many culture-specific virtues, and perhaps even modules. Nnate Mind 2007, 3, 367-391.

26. Butarbutar, I.; Härtel, C.; Hirst, G.; Pekerti, A.; Sendjaya, S. Are authentic leaders always moral? The role of machiavellianism in the relationship between authentic leadership and morality. J. Bus. Ethics 2016, 133, 125-139.

27. Poulshock, J.W. Language and Morality: Evolution, Altruism, and Linguistic Moral Mechanisms. Ph.D. Thesis, University of Edinburgh, Edinburgh, UK, 2006.

28. Costa, A.; Foucart, A.; Hayakawa, S.; Aparici, M.; Apesteguia, J.; Heafner, J.; Keysar, B. Your morals depend on language. PLoS ONE 2014, 9, e94842. [CrossRef] [PubMed]

29. Lakoff, G. Cognitive semantics: In the heart of language an interview with George Lakoff. Fórum Linguístico 1998, 1, 83-119.

30. Dahl, A.; Killen, M. A Developmental perspective on the origins of morality in infancy and early childhood. Front. Psychol. 2018, 9, 1736. [CrossRef] [PubMed]

31. Decety, J.; Greene, J.; Wheatley, T. The Moral Brain ... and What to do About It; Penguin: New York, NY, USA, 2015.

32. Lind, G. Moral Competence Test (MCT) 2014. Available online: https://www.uni-konstanz.de/ag-moral/ kurse/2015_AME_Santos/Lind-2015_MCT\%20Moral_Competence_Test_e4.pdf (accessed on 2 May 2020).

33. Hummel, K.; Pfaff, D.; Rost, K. Does economics and business education wash away moral judgment competence? J. Bus. Ethics 2018, 150, 559-577. [CrossRef]

34. Mofakhami, A. The Effect of Moral Competence on online Conformity Behavior. 2019. Available online: https: //pdfs.semanticscholar.org/db95/6efd87a9c15dc5fd8914ffd6db84e6916657.pdf (accessed on 19 June 2020).

35. Klimenko, M.A.; Sofia, F.M. Hey! Listen! Just because it’s violent doesn't mean it's inmoral. Psychol. Pop. Media Cult. 2019, 8, 251-258. 
36. Klimenko, M.; Surdel, N.; Muir, K.; Sofia, F. Can online college education make students smarter and more moral? A preliminary study of the effects of two online college course assignments on students' moral competence. Ethics Prog. 2018, 9, 44-55. [CrossRef]

37. Cunha, M.; Durte, J.; Silva, E.; Silva, D.; Pina, J. Reasoning and moral judgement in higher education students: Reality and challenge. Turk. Online J. Educ. Technol. November Spec. Issue 2017, 812-824.

38. Mouratidou, K. Determinants of athletes'moral competence: The role of demographic characteristics and sport-related perceptions. Sport Soc. 2017, 20, 802-815. [CrossRef]

39. Neves Feitosa, H.; Rego, S.; Unger Raphael, P.; Castelo Branco, K.F.; Rego, G.; Nunes, R. Moral judgement competence of medical students: A transcultural study. Adv. Health Sci. Educ. 2013, 18, 1067-1085. [CrossRef] [PubMed]

40. Ministerio de Política Territorial y Función Pública. El Perfil del Concejal Español: Un Hombre Entre 26 y 45 Años, Con Estudios Elementales y Que Repite Mandato. 2009. Available online: https://www.mptfp.gob. es/portal/prensa/notas_de_prensa/notas/2009/08/20090825.html (accessed on 7 May 2020).

41. Crocetti, E.; Moscatelli, S.; Kaniusonytè, G.; Meeus, W.; Zukauskienè, R.; Rubino, M. Developing Moralitym competence, and sociability in adolescence: A longitudinal study of gender differences. J. Youth Adolesc. 2019, 48, 1009-1021. [CrossRef] [PubMed]

42. Mahasneh, A.M. The level of moral competence among sample of Hashemite university students. Middle-East J. Sci. Res. 2014, 19, 1259-1265.

43. Ministerio de Educación y Formación Profesional. Panorama de educación. Indicadores de la OCDE. Informe Español. 2019. Available online: http://www.educacionyfp.gob.es/inee/dam/jcr:4689798f-5c6b4bab-b5fe-58ad7004c6fd/panorama\%20de\%20la\%20educaci\%C3\%B3n\%202019-1\%C3\%ADnea-def.pdf (accessed on 27 April 2020).

44. Agurto, M.; Telloa, D.; Elgueta, A.; Larrea, R.; Minaeff, T.; Miranda, A.; Parodi, E.; Salas, J.M.; Vukusich, A.; Llanos, S.; et al. Assessment of moral competence of physicians. Rev. Médica de Chile 2017, 145, 1122-1128. [CrossRef]

45. Friedrich, O.; Hemmerling, K.; Kuehlmeyer, K.; Nörtemann, S.; Fischer, M.; Marckmann, G. Principle' based structured case discussions: Do they foster moral competence in medical students? A pilot study. BMC Med. Ethics 2017, 18, 1-8. [CrossRef]

46. Abbasi, W.G.; Shakir, S.; Azhaar, M.; Arif, P.; Shariff, N.; Syed, H. Effect of medical education on the moral competence of medical students. In Proceedings of the 4th International Conference on Arts and Humanities, Colombo, Sri Lanka, 21-22 September 2017; 4, pp. 127-140. [CrossRef]

47. Maluwa, V.M.; Gwaza, E.; Sakala, B.; Kapito, E.; Mwale, R.; Haruzivishe, C.; Chirwa, E. Moral competence among nurses in Malawi: A concept analisys approach. Nurs. Ethics 2019, 26, 1361-1372. [CrossRef] [PubMed]

48. Ley Orgánica 3/2007, de 22 de marzo, para la igualdad efectiva de mujeres y hombres. Boletín Of. del Estado 2007, 71, 12611-12645. Available online: https://www.boe.es/eli/es/lo/2007/03/22/3/con (accessed on 8 May 2020).

49. Gross, M.L. Moral reasoning and ideological affiliation: A cross-national study. Political Psychol. 1996, 17, 317-338. [CrossRef]

50. Saribay, S.A.; Yilmaz, O. Moral foundations explain unique variance in political ideology beyond resistance to change and opposition to equality. Group Process. Intergroup Relat. 2019, 22, 1124-1138.

51. Beussink, C.; Gay, J.G.; Lishner, D.A.; Vitacco, M.J. Deconstructing the association between psychopathy and political orientation: Is it attributable to moral intuitions or moral competency? Personal. Individ. Differ. 2019, $149,128-134$.

52. Crabtree, C.; Hatemi, P.K.; Smith, K.B. Ideology Justifies Morality: Political Beliefs Predict Moral Foundations. Am. J. Political Sci. 2019, 63, 788-806.

53. Trechera, L. Translation and Validation of the Spanish version of he Moral Judgement Test. University of Córdoba: Spain, 1996. Available online: https:/www.uni-konstanz.de/ag-moral/mut/validation/MJTspanish-1996-validation-trechera.pdf (accessed on 8 May 2020).

54. Lind, G. Making moral competence visible. In Book How to Teach Moral Competence; Lind, G., Ed.; Logos: Berlin, Germany, 2019; Available online: http://www.uni-konstanz.de/ag-moral/pdf/Lind-2019_How_to_ teach_moral_competence_ch_4.pdf (accessed on 17 May 2020). 
55. Lind, G. Studies on the Measurement, Nature and Development of Moral- Competence (MCT) 2020. Available online: http://www.uni-konstanz.de/ag-moral/mut/mjt-references.htm (accessed on 18 April 2020).

56. Biggs, D.A.; Colesante, R.J. The Moral Competence Test: An examination of validity for samples in the United States. J. Moral Educ. 2015, 44, 497-515. [CrossRef]

57. Ley Orgánica 5/1985, de 19 de junio, del Régimen Electoral General. Boletín Of. del Estado. Available online: https://www.boe.es/buscar/act.php?id=BOE-A-1985-11672 (accessed on 9 May 2020).

58. Duriez, B.; Soenens, B. Religiosity, moral attitudes and moral competence: A critical investigation of the religiosity-morality relation. Int. J. Behav. Dev. 2006, 30, 76-83. [CrossRef]

59. Lajčiaková, P. Social Work Students' Moral Judgement Competence. Spec. Engl. 2013, 2013, 51.

60. Lind, G. Wie Misst Man Moralisches Urteil? Probleme und Alternative Möglichkeiten der Messung Eines Komplexen Konstrukts; Beltz: Weinheim, Germany, 1978; pp. 171-201. Available online: http://lind-kurs: kohlberg@www.uni-konstanz.de/ag-moral/pdf/Lind-1978_MUT-in-Portele.pdf (accessed on 19 June 2020).

61. Colby, A.; Kohlberg, L. The Measurement of Moral Judgment; Cambridge University Press: New York, NY, USA, 1987.

62. Rest, J. Development in Judging Moral Issues; University Minnesota Press: Minneapolis, MN, USA, 1979.

(C) 2020 by the authors. Licensee MDPI, Basel, Switzerland. This article is an open access article distributed under the terms and conditions of the Creative Commons Attribution (CC BY) license (http://creativecommons.org/licenses/by/4.0/). 